\title{
Sensitivity of global cloud condensation nuclei concentrations to primary sulfate emission parameterizations
}

\section{G. Luo and F. Yu}

Atmospheric Sciences Research Center, State University of New York, 251 Fuller Road, Albany, New York 12203, USA

Received: 6 November 2010 - Published in Atmos. Chem. Phys. Discuss.: 12 November 2010

Revised: 19 February 2011 - Accepted: 22 February 2011 - Published: 3 March 2011

\begin{abstract}
The impact of primary sulfate emissions on cloud condensation nuclei $(\mathrm{CCN})$ concentrations, one of the major uncertainties in global CCN predictions, depends on the fraction of sulfur mass emitted as primary sulfate particles $\left(f_{\text {sulfate }}\right)$, the fraction of primary sulfate mass distributed into the nucleation mode particles $\left(f_{\text {nucl }}\right)$, and the nucleation and growth processes in the ambient atmosphere. Here, we use a global size-resolved aerosol microphysics model recently developed to study how the different parameterizations of primary sulfate emission affect particle properties and CCN abundance. Different from previous studies, we use the ionmediated nucleation scheme to simulate tropospheric particle formation. The kinetic condensation of low volatile secondary organic gas (SOG) (in addition to $\mathrm{H}_{2} \mathrm{SO}_{4}$ gas) on nucleated particles is calculated based on our new scheme that considers the SOG volatility changes arising from the oxidation aging. Our simulations show a compensation effect of nucleation to primary sulfate emission. We find that the change of $f_{\text {nucl }}$ from $5 \%$ to $15 \%$ has a more significant impact on the simulated particle number budget than that of $f_{\text {sulfate }}$ within the range of $2.5-5 \%$. Based on our model configurations, an increase of $f_{\text {sulfate }}$ from $0 \%$ to $2.5 \%$ (with $f_{\text {nucl }}=5 \%$ ) does not improve the agreement between simulated and observed annual mean number concentrations of particles $>10 \mathrm{~nm}$ at 21 stations but further increase of either $f_{\text {sulfate }}$ from $2.5 \%$ to $5 \%$ (with $f_{\text {nucl }}=5 \%$ ) or $f_{\text {nucl }}$ from $5 \%$ to $15 \%$ (with $f_{\text {sulfate }}=2.5 \%$ ) substantially deteriorates the agreement. For $f_{\text {sulfate }}$ of $2.5 \%-5 \%$ and $f_{\text {nucl }}$ of $5 \%$, our simulations indicate that the global $\mathrm{CCN}$ at supersaturation of $0.2 \%$ increases by $8-11 \%$ in the boundary layer and $3-5 \%$ in the whole troposphere (compared to the case with $f_{\text {sulfate }}=0$ ).
\end{abstract}

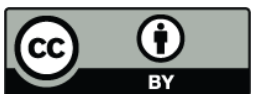

Correspondence to: G. Luo

(ganluo@asrc.albany.edu)

\section{Introduction}

Atmospheric aerosols significantly impact climate system via direct and indirect radiative effects (IPCC, 2007). Aerosols can affect climate directly by scattering and absorbing solar radiation, reducing surface temperature, and changing the patterns of atmospheric circulation (Luo et al., 2009). Atmospheric particles can affect climate indirectly by acting as cloud condensation nuclei ( $\mathrm{CCN})$, modifying cloud properties, altering precipitation, and changing global radiation and heat budgets (Twomey, 1977; Albrecht, 1989). The aerosol indirect effect is largely controlled by the CCN abundance which depends on particle size distributions and compositions. One of the uncertainties in global CCN simulations is associated with the parameterization of sub-grid sulfur oxidation and sulfate particle formation in anthropogenic $\mathrm{SO}_{2}$ plumes which has been named "primary sulfate" emissions in the literature.

Uncertainties associated with primary sulfate emissions mainly arise from two parts: (1) fraction of sulfur mass emitted as sulfate particles $\left(f_{\text {sulfate }}\right)$; and (2) parameterization of primary sulfate particle number size distribution. $f_{\text {sulfate }}$ is employed to account for the sulfur oxidation and new particle formation occurring in the sub-grid scale anthropogenic $\mathrm{SO}_{2}$ plumes. $f_{\text {sulfate }}$ values ranging from $0 \%$ to $5 \%$ have been assumed in various global modeling studies (Adams and Seinfeld, 2002, 2003; Spracklen et al., 2005a, b; Pierce and Adams, 2006; Spracklen et al., 2008; Makkonen et al., 2009; Pierce and Adams, 2009; Wang and Penner, 2009; $\mathrm{Yu}$ and Luo, 2009). The exact value of $f_{\text {sulfate }}$ at each grid cell is expected to depend on $\mathrm{OH}$ concentration (e.g., Wilson, 1981) and model resolution. Primary sulfate emitted in the power plant plume is generally distributed into two lognormal modes with geometric number-based mean diameters $\left(d_{\mathrm{g}}\right)$ of $10 \mathrm{~nm}$ (nucleation mode) and $70 \mathrm{~nm}$ (accumulation or condensation mode) with standard deviations $(\sigma)$ of 1.6

Published by Copernicus Publications on behalf of the European Geosciences Union. 
and 2.0, respectively (Whitby, 1978; Whitby et al., 1978). The limited observations presented in Whitby et al. (1978) suggested that the fraction of primary sulfate in the nucleation mode $\left(f_{\text {nucl }}\right)$ is $5 \%$ (called Whitby 78 value thereafter) while the remaining (95\%) of sulfate is in the accumulation mode (i.e., $f_{\text {accu }}=95 \%$ ). It is expected that $f_{\text {nucl }}$ value has large uncertainty. Many of the above mentioned global aerosol studies assume $f_{\text {nucl }}=15 \%$ (e.g., Adams and Seinfeld, 2002; Wang and Penner, 2009) while several other studies asume $f_{\text {nucl }}=0 \%$ (Makkonen et al., 2009) or 5\% (Yu and Luo, 2009). The impacts of the different assumptions of primary sulfate particle number size distribution (or $f_{\text {nucl }}$ values) on simulated global aerosol properties have not yet been assessed.

For any given $f_{\text {sulfate }}$ and $f_{\text {nucl }}$ values, the contribution of primary sulfate emission to the global $\mathrm{CCN}$ abundance depends strongly on the particle nucleation schemes used in the model to predict particle nucleation rates in the ambient troposphere as well as the assumptions of other primary particles. For example, Adams and Seinfeld (2003) showed that $3 \%$ of anthropogenic sulfur emitted as particulate sulfate increases $\mathrm{CCN}$ concentrations in polluted areas by up to $\sim 200-500 \%$. Spracklen et al. (2005b) showed that global mean sulfate and sea salt derived CCN concentrations change by up to $27 \%$ in marine boundary layer and by more than $100 \%$ over some continental regions when the fraction of anthropogenic $\mathrm{SO}_{2}$ emitted as particulates is increased from 0 to 5\%. It should be noted that Adams and Seinfeld (2003) did not consider primary particles other than primary sulfate and Spracklen et al. (2005b) only had sulfate and seasalt (i.e., no primary OC, soot, and dust) in their simulations. Both studies employed binary homogeneous nucleation $(\mathrm{BHN})$ to calculate new particle formation rate. The large sensitivity of $\mathrm{CCN}$ to primary sulfate assumption found in these two studies is partially due to the small BHN rate in the boundary layer and partially due to the lack of other primary particles. Pierce and Adams (2009) reported that global mean CCN number concentrations increased $17 \%$ in the whole troposphere and $40 \%$ in the boundary layer, when primary aerosol emissions (sulfate, $\mathrm{BC}, \mathrm{OC}$ and so on) were increased by a factor of 3 and BHN scheme was used to calculate new particle formation. These changes drop to $3 \%$ and $22 \%$, respectively, when the nucleation rates were calculated based on the ternary homogeneous nucleation (THN) model. Wang and Penner (2009) estimated the impacts of primary sulfate emission on $\mathrm{CCN}$ abundance using two different nucleation schemes: one based on BHN for the whole troposphere and the other using the empirical activation-type nucleation mechanism in the boundary layer and the BHN mechanism above boundary layer (BHN_EMP). Wang and Penner (2009) showed that, when $f_{\text {sulfate }}$ increases from $0 \%$ to $2 \%$, CCN concentration in the lower boundary layer increases by $53 \%$ based on BHN while it increases by $23 \%$ based on BHN EMP parameterization.
It is well known that uncertainty in $\mathrm{CCN}$ concentration could lead to large uncertainty in aerosol indirect radiative forcing. Based on the relationship between cloud albedo $(A)$ and $\mathrm{CCN}$ concentration $(N)$ given in Platnick and Twomey (1994) $(\Delta A / A=(1-A) / 3 \times \Delta N / N)$, a $10 \%$ of increase in $\mathrm{CCN}$ concentrations can lead to $\sim 2 \%$ increase in average cloud albedo (assuming global average $A$ of 0.42 , Han et al., 2001). Since clouds on average reflect about $50 \mathrm{~W} \mathrm{~m}^{-2}$ of incoming solar radiation back to space (Hartmann, 1993), a $2 \%$ increase in the average cloud albedo could lead to a radiative forcing of $\sim 1 \mathrm{~W} \mathrm{~m}^{-2}$. While these estimations are crude, they do indicate the importance in reducing the uncertainty in global CCN predictions.

The main objective of this study is to carry out a comprehensive investigation of how primary sulfate emissions may influence $\mathrm{CCN}$ abundance in the global atmosphere, using a global size-resolved (sectional) aerosol microphysics model (Yu and Luo, 2009). Different from previous assessments on the impact of primary sulfate emission parameterizations, we use the ion-mediated nucleation (IMN) scheme (Yu et al., 2008; Yu, 2010; Yu et al., 2010) to calculate new particle formation in the troposphere. In addition, we explicitly consider the condensation of low-volatile SOG arising from the oxidation aging process on nucleated particles based on the recently developed extended secondary organic aerosol (SOA) formation mechanism (Yu, 2011) which is different from the treatment of SOA condensation in several previous global modeling studies (e.g., Spracklen et al., 2008; Pierce and Adams, 2009). The effects of $f_{\text {nucl }}$ values on simulated CCN concentrations, which have not been investigated in previous studies, are also investigated in this study. The physics behind the impacts of primary sulfate emission is analyzed in detail by comparing condensation sinks, nucleation rates, and particle size distributions simulated with different primary sulfate emission assumptions.

\section{Model description and overview of simulations}

The GEOS-Chem 3-D chemical transport model, with an advanced particle microphysics (APM) model incorporated (Yu and Luo, 2009), is employed for this study. Large-scale atmospheric transport is specified from the assimilated meteorological observations from the Goddard Earth Observing System (GEOS) of the NASA Global Modeling Assimilation Office (GMAO). The GEOS-Chem model includes a detailed simulation of tropospheric ozone-NOx-hydrocarbon chemistry as well as of aerosols and their precursors (Park et al., 2004). Aerosol and gas-phase simulations are coupled through sulfate and nitrate formation, heterogeneous chemistry (Evans and Jacob, 2005), aerosol effects on photolysis rates (Martin et al., 2003), and secondary organic aerosol (SOA) formation (Liao et al., 2007). The ISORROPIA thermodynamic equilibrium model (Fountoukis and Nenes, 2007) is used to calculate partitioning of total ammonia and nitric acid between the gas and aerosol phases. 
A detailed description of the GEOS-Chem model (including the treatment of various emission sources, chemistry and aerosol schemes) can be found in the model webpage (http://acmg.seas.harvard.edu/geos/index.html).

The present version of the APM module in GEOS-Chem employs 40 bins for sulfate to cover the dry diameter size range of $0.0012 \mu \mathrm{m}$ to $12 \mu \mathrm{m}$, and 20 bins for sea salt to cover the dry diameter size range of $0.012 \mu \mathrm{m}$ to $12 \mu \mathrm{m}$ (Yu and Luo, 2009). The first bin of sulfate particles corresponds to the sizes of freshly nucleated particles in the atmosphere which generally have a dry diameter of $\sim 0.0012 \mu \mathrm{m}$ (Yu and Turco, 2008), therefore it does not need to scale the nucleated particles to the first bin particles. The sulfate aerosols are internally mixed with nitrate, ammonium and organics in our model, and the contributions of nitrate, ammonium, and SOAs to sulfate particle growth are considered through equilibrium uptake (Yu and Luo, 2009). An extended secondary organic aerosol formation mechanism developed by Yu (2011) has been employed in this study to transfer medium-volatile SOG to semi-volatile SOG and semi-volatile SOG to low-volatile SOG associated with oxidation aging (e.g., Jimenez et al., 2009). This treatment significantly increases the growth rates of nucleated particles associated with the condensation of low-volatile SOG (compared to the original SOA formation scheme in GEOSChem), which is consistent with many field measurements and important for properly accounting for the contribution of nucleated particles to CCN (Yu, 2011). When we calculate the CCN activation, we use the dry size (sulfate + uptaken equilibrium nitrate, ammonium, and SOA) to reflect the contribution of multiple components (Yu and Luo, 2009). The model also considers the scavenging of secondary particles by primary particles such as BC, OC, dust, and sea salt. In the current model, the condensation of sulfuric acid, in-cloud $\mathrm{SO}_{2}$ oxidation and the coagulation scavenging of secondary sulfate particles by primary particles are simulated by using four separate tracers (BC_sulfate, OC_sulfate, Dust_sulfate, and SeaSalt_sulfate) to keep track of the bulk sulfate mass associated with $\mathrm{BC}, \mathrm{OC}$, dust, and sea salt, respectively. When some of $\mathrm{BC}, \mathrm{OC}$, dust, and sea salt are removed from the atmosphere via dry and wet deposition, the corresponding portions of sulfate associated with these particles are also removed. A more detailed description of the APM module, which will be added to the standard version of GEOS-Chem in the near future after further improvements, can be found in Yu and Luo (2009).

In the simulations presented here, we use a horizontal resolution of $4^{\circ} \times 5^{\circ}$ and 47 vertical layers up to $0.01 \mathrm{hpa}$ (GEOS-5 meteorological fields). The global sulfur emission is based on the Emissions Database for Global Atmospheric Research (EDGAR) inventory v3.2 (Olivier et al., 2001), while the emissions in the United States, Canada, Mexico, Europe and East Asia are replaced by the regional emission inventories including the Environmental Protection Agency's National Emission Inventory 2005, the Criteria Air Contam- inants (CAC) Emissions Inventory, the Big Bend Regional Aerosol and Visibility Observational (BRAVO) Study Emissions Inventory (Kuhns et al., 2003), the European Monitoring and Evaluation Programme (EMEP) Emissions Inventory, and the Transport and Chemical Evolution over the Pacific (TRACE-P) Emissions Inventory (Streets et al., 2003). The model also includes other primary particle emissions such as black carbon (BC), primary organic carbon (POC), dust, and sea salt. A detailed description of other key gaseous species and parameterizations of various primary particle emissions can be found in Yu and Luo (2009).

Four simulations, which are summarized in Table 1, have been run to quantify the impacts of primary sulfate emission on nucleation, particle number size distribution, and $\mathrm{CCN}$ number concentration. In our study, following the parameterizations given in Whitby (1978) and Whitby et al. (1978), we assume that $f_{\text {nucl }}$ of primary sulfate mass is emitted in the nucleation mode $\left(d_{\mathrm{g}}=10 \mathrm{~nm}, \sigma=1.6\right)$ while the rest in the accumulation mode which has been treated as condensation on $\mathrm{BC}$ and primary OC particles ( $\mathrm{Yu}$ and Luo, 2009). The FS0 simulation assumes $f_{\text {sulfate }}=0$ (i.e., no primary sulfate emission). The FS2.5FN5 simulation, which assumes $f_{\text {sulfate }}=2.5 \%$ with $f_{\text {nucl }}=5 \%$ and $f_{\text {accu }}=95 \%$, is used as the baseline simulation. The FS2.5FN15 simulation corresponds to the case for $f_{\text {sulfate }}=2.5 \%$ with $f_{\text {nucl }}=15 \%$ and $f_{\text {accu }}=85 \%$. The comparison of the FS2.5FN5 and FS2.5FN15 simulations allows us to see how the $f_{\text {nucl }}$ value may affect the simulations of CCN number concentrations. The FS5FN5 simulation, which is the same as the FS2.5FN5 simulation except that $f_{\text {sulfate }}$ is increased from $2.5 \%$ to $5 \%$, is designed to provide further insight into how $f_{\text {sulfate }}$ value may impact the simulated particle properties and $\mathrm{CCN}$ number concentrations. The net effects of $f_{\text {sulfate }}$ and $f_{\text {nucl }}$ on the primary sulfate emission can be easily interpreted by comparing FS2.5FN5 to FS0, FS2.5FN15 and FS5FN5, respectively. The spin-up time of our simulations is two months (November-December 2004). All annually averaged results shown in this paper are for year 2005.

\section{Results and discussion}

\subsection{Impact of primary sulfate emissions on nucleation rates}

In addition to directly injected particles into the grid boxes, primary sulfate emissions indirectly impact the particle number budget via influencing sulfur dioxide concentration (noting that $1-f_{\text {sulfate }}$ of anthropogenic sulfur emitted as $\mathrm{SO}_{2}$ ), condensation sink (CS), sulfuric acid gas concentration $\left(\left[\mathrm{H}_{2} \mathrm{SO}_{4}\right]\right)$, and hence new particle formation rates. Figure 1 shows how different primary sulfate emission assumptions affect $\mathrm{CS}$ in the atmosphere. With the exclusion of primary sulfate emission, CS near source regions is decreased by up to $\sim 10-20 \%$ (Fig. 1b), while the zonally averaged 

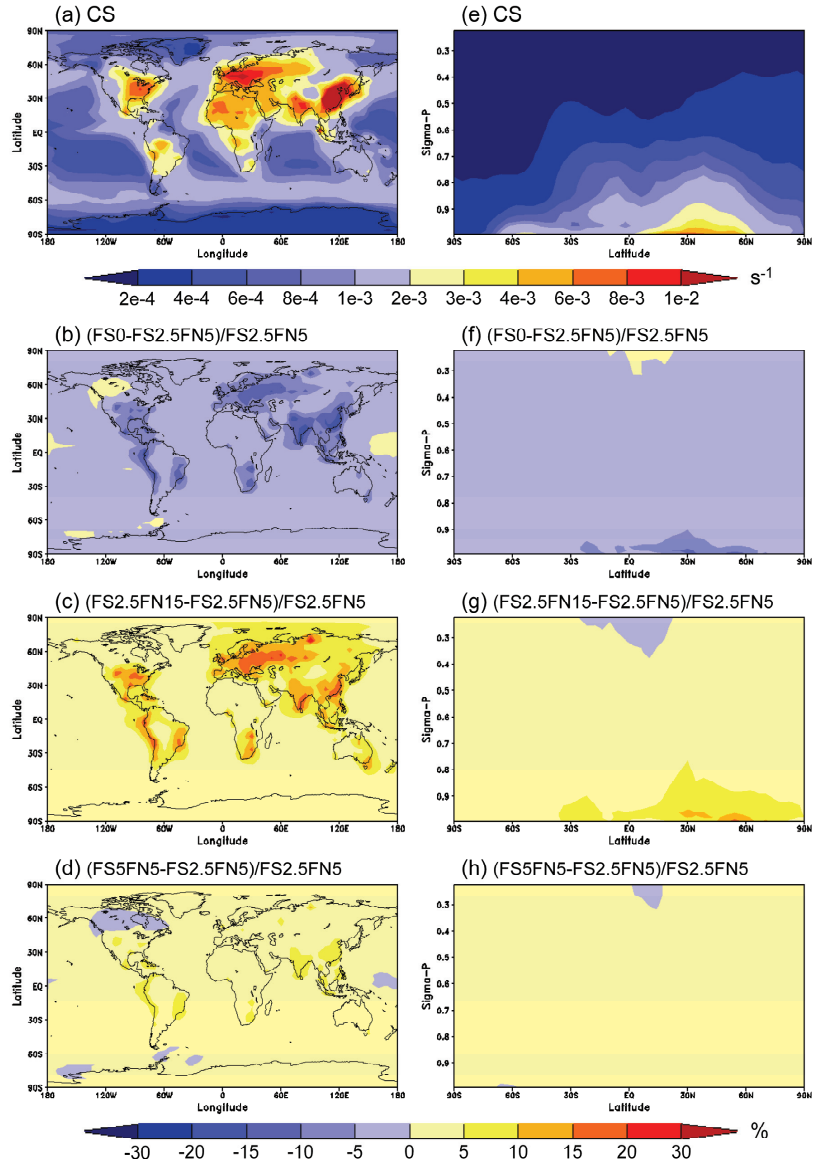

Fig. 1. (a) Horizontal distribution of annual mean condensational sink (CS) in the boundary layer $(0-1 \mathrm{~km})$ and (e) zonally-averaged vertical profile of annual mean CS for the baseline case simulation (i.e., case FS2.5FN5 in Table 1). (b-d) and (f-h) give the corresponding horizontal and vertical percentage changes of CS induced by different primary sulfate emission parameterizations. FS0, FS2.5FN5, FS2.5FN15 and FS5FN5 are the cases defined in Table 1.

relative changes at the Northern Hemisphere mid-latitude regions $\left(30^{\circ} \mathrm{N}-60^{\circ} \mathrm{N}\right)$ is decreased by about $5-10 \%$ in the low boundary layer (Fig. 1f). In northwestern Canada, CS is increased by $\sim 0-5 \%$ due to the increased concentration of freshly nucleated particles. It can be clearly seen from Fig. 1c and $g$ (the FS2.5FN15 case) that CS is very sensitive to the $f_{\text {nucl }}$ values. The increased primary sulfate mass in the nucleation mode significantly increases the CS and thus decreases $\left[\mathrm{H}_{2} \mathrm{SO}_{4}\right]$ (not shown). Figure 1d indicate that $\mathrm{CS}$ is increased by $5-10 \%$ over source regions when $f_{\text {sulfate }}$ is increased from $2.5 \%$ to $5 \%$. It is clear that the impact of $f_{\text {sulfate }}$ increased from $2.5 \%$ to $5 \%$ on CS is much smaller than that of $f_{\text {nucl }}$ changed from $5 \%$ to $15 \%$.

Compared to the baseline case (FS2.5FN5), nucleation rate is increased in the FS0 case and decreased in the FS2.5FN15 and FS5FN5 cases (Fig. 2) as a response to the
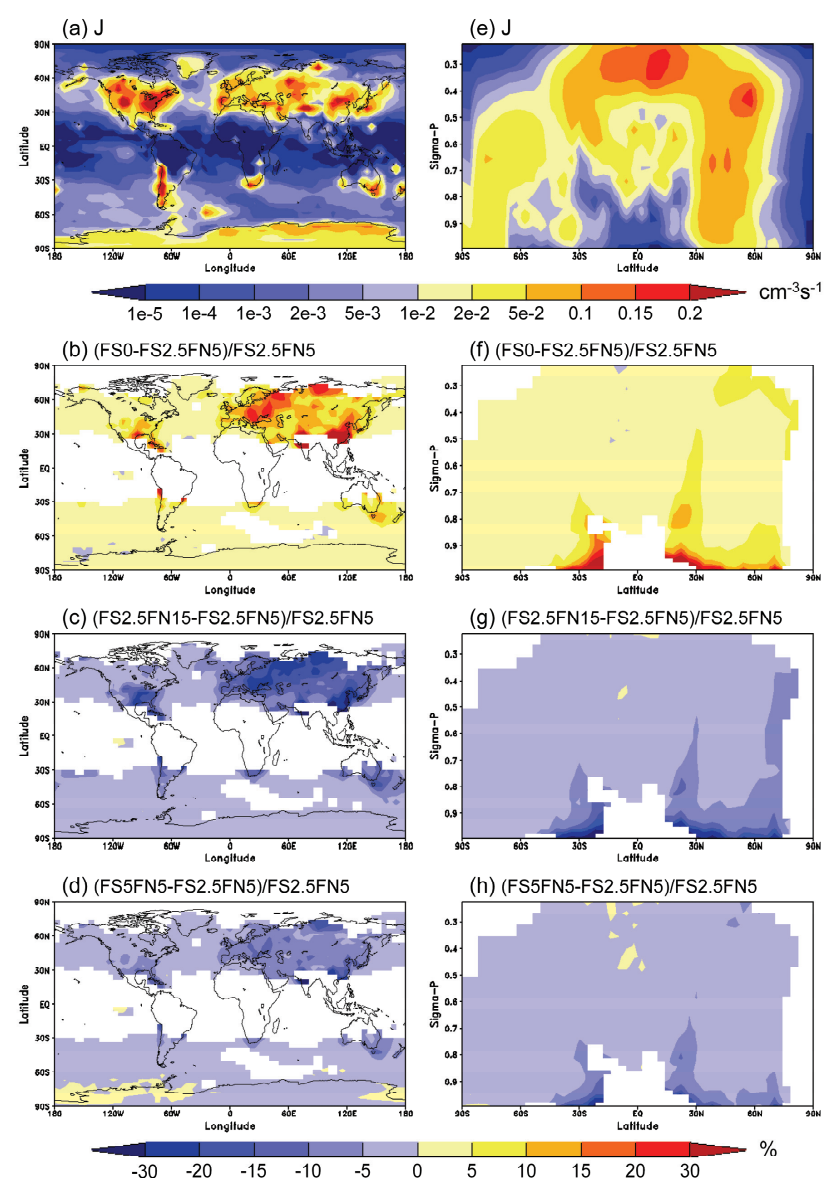

Fig. 2. Same as Fig. 1, except for the nucleation rate $(J)$.

Table 1. Overview of the four simulations presented in this work.

\begin{tabular}{lrrrr}
\hline & FS0 & FS2.5FN5 & FS2.5FN15 & FS5FN5 \\
\hline$f_{\text {sulfate }}$ & 0 & $2.5 \%$ & $2.5 \%$ & $5 \%$ \\
$f_{\text {nucl }}$ & 0 & $5 \%$ & $15 \%$ & $5 \%$ \\
$f_{\text {accu }}$ & 0 & $95 \%$ & $85 \%$ & $95 \%$ \\
\hline
\end{tabular}

$f_{\text {sulfate }}$ is the fraction of anthropogenic sulfur mass emitted as primary sulfate particles, which is used to represent sub-grid $\mathrm{SO}_{2}$ oxidation and sulfate particle formation in anthropogenic sulfur plumes; $f_{\text {nucl }}$ is the fraction of primary sulfate mass in the nucleation mode; $f_{\text {accu }}$ is the fraction of primary sulfate mass distributed into the accumulation mode.

changes of $\mathrm{CS}$ and $\left[\mathrm{H}_{2} \mathrm{SO}_{4}\right]$. Figure 2a shows the high values of low boundary layer nucleation rate are mainly located over the Northern Hemisphere mid-latitude regions $\left(30^{\circ} \mathrm{N}-\right.$ $60^{\circ} \mathrm{N}$ ). Nucleation is sensitive to the changes of $\left[\mathrm{H}_{2} \mathrm{SO}_{4}\right]$. The decrease of $\left[\mathrm{H}_{2} \mathrm{SO}_{4}\right]$, caused by the enhanced CS associated with the increased primary sulfate particles and reduced fraction of anthropogenic sulfur emitted as $\mathrm{SO}_{2}$ gas, decreases the intensity of nucleation in the atmosphere. In and near the anthropogenic sulfur source regions, nucleation 

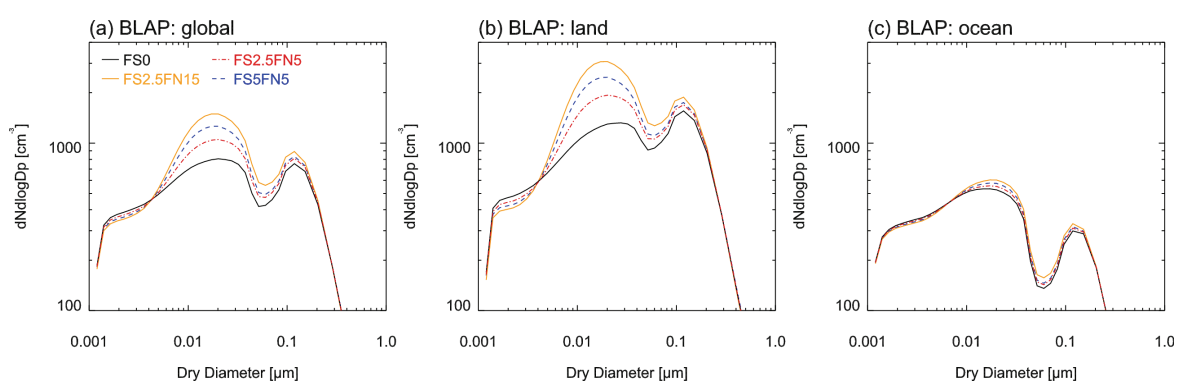

Fig. 3. Simulated boundary layer aerosol particles (BLAP) number size distributions over (a) global, (b) land, and (c) ocean. Black, red, yellow and blue curves represent the FS0, FS2.5FN5, FS2.5FN15, and FS5FN5 cases, respectively.

rates increase by up to $\sim 10-30 \%$ when $f_{\text {sulfate }}$ changes from $2.5 \%$ to $0 \%$ (Fig. $2 \mathrm{~b}$ and f), and decrease by $\sim 10-30 \%$ when $f_{\text {nucl }}$ changes from $5 \%$ to $15 \%$ (at fixed $f_{\text {sulfate }}=2.5 \%$, Fig. 2c and g). The FS5FN5 case has less impact on nucleation rates compared to the FS2.5FN15 case. It should be noted that the lower nucleation rates over tropical lower troposphere (annual mean $J<\sim 0.001 \mathrm{~cm}^{3} \mathrm{~s}^{-1}$, Fig. 2a and e) lead to high percentage changes in $\mathbf{J}$ values in the regions but such changes are insignificant to particle number budget there and thus have been blocked out in Fig. $2 b-d$ and $f-h$ to highlight the changes in major source regions.

The results given in Fig. 2 clearly show a compensation effect of nucleation to primary sulfate emission. Reduced primary sulfate emission (lower $f_{\text {sulfate }}$ and/or $f_{\text {nucl }}$ ) reduces the surface area of primary particles directly injected into the grid boxes resulting in an increase in new particle formation rates near the source regions. The increased nucleation rates compensate for some of the primary sulfate number emission reductions. Nevertheless, as we will show in the next several sections, the increased concentrations of freshly nucleated particles are less than the decreased concentrations of primary sulfate particles over the source regions. In other words, enhanced nucleation cannot fully replace the role of sub-grid scale sulfur oxidant and nucleation processes within the plume. Therefore, proper parameterizations of these subgrid processes are still needed.

\subsection{Impact of primary sulfate emissions on particle number size distributions}

To analyze how different primary sulfate emission assumptions and associated nucleation rate changes may impact the global aerosol properties, we plot in Fig. 3 the simulated annual mean particle number size distributions in the boundary over land (b) and over ocean (c) as well as those averaged in the global boundary layer (Fig. 3a). It can be clearly seen that the impacts of primary sulfate emission on aerosol number size distributions are substantial in the boundary layer over land (Fig. 3b) but are small over the ocean (Fig. 3c). In addition to the direct influence on the concentrations of primary sulfate particles emitted into certain grid boxes, pri- mary sulfate parameterizations also affect the total particle size distributions by influencing condensation sink, $\mathrm{H}_{2} \mathrm{SO}_{4}$ vapor concentration, and particle nucleation and growth rate. Figure 3 a shows that boundary layer aerosol number size distribution has three modes. The first mode appears at the dry diameter of $\sim 2.5 \mathrm{~nm}$. Particles in this mode are formed via nucleation of sulfuric acid gas and water vapor. We call this the freshly nucleated mode. The second and third modes appear at the dry diameters of $\sim 20 \mathrm{~nm}$ and $\sim 120 \mathrm{~nm}$, which are known as Aitken and accumulation modes, respectively. The FSO simulation (black line) indicates that freshly nucleated particles can grow to the size of Aitken mode particles. The number concentrations of freshly nucleated mode particles decrease while those of Aitken mode particles and accumulation mode particles increase with the increase of $f_{\text {sulfate }}$ and $f_{\text {nucl }}$. Based on the FS2.5FN5 (red line), FS2.5FN15 (orange line) and FS5FN5 (blue line) simulations, we find that the change of $f_{\text {nucl }}$ from $5 \%$ to $15 \%$ has a more significant impact on boundary layer aerosol number size distributions than that of $f_{\text {sulfate }}$ within the range of $2.5-5 \%$. As shown in Fig. $3 b$ and $c$, the impacts of primary sulfate emission on boundary layer aerosol number size distribution over land and ocean are quite different. The difference in the boundary layer aerosol number size distribution among all four cases is negligible over the oceans but is substantial over land. In the boundary layer over land, the number concentrations of freshly nucleated mode, Aitken mode and accumulation mode particles in the FS2.5FN15 simulation are $\sim 0.8$, $\sim 1.9$ and $\sim 1.2$ of those in the FS0 simulation (Fig. $3 b$ ). The changes of primary sulfate emission have negligible impact on aerosol number size distribution averaged over the whole troposphere (not shown).

\subsection{Impact of primary sulfate emissions on number concentrations of particles larger than $10 \mathrm{~nm}(\mathrm{CN10})$ and comparisons with measurements}

Figure 4 shows the horizontal and vertical spatial distributions of annual mean CN10 (Fig. 4a, e) and its responses to the changes of primary sulfate emissions (Fig. $4 \mathrm{~b}-\mathrm{d}, \mathrm{f}-$ h). Direct injection of nucleation mode particles with median 
Table 2. Mean number concentrations of condensation nuclei larger than $10 \mathrm{~nm}(\mathrm{CN} 10)$ measured in 21 surface stations around the globe. The simulated values for the FS0, FS2.5FN5, FS2.5FN15, and FS5FN5 sensitivity study cases are from the corresponding locations in GEOS-Chem.

\begin{tabular}{|c|c|c|c|c|c|c|}
\hline & & Obs. & FS0 & FS2.5FN5 & FS2.5FN15 & FS5FN5 \\
\hline \multicolumn{7}{|c|}{ Location or Station Name } \\
\hline A & Point Barrow, AK, USA & $231^{\mathrm{a}}$ & 293 & 317 & 377 & 341 \\
\hline B & Pallas-Sammaltunturi, Finland & $802^{\mathrm{a}}$ & 713 & 877 & 1202 & 999 \\
\hline $\mathrm{C}$ & Värriö, Finland & $823^{\mathrm{b}}$ & 944 & 1215 & 1731 & 1407 \\
\hline $\mathrm{D}$ & Hyytiälä, Finland & $2016^{\mathrm{b}}$ & 1972 & 2485 & 3334 & 2794 \\
\hline $\mathrm{E}$ & Uto, Baltic Sea & $2921^{\mathrm{b}}$ & 1972 & 2485 & 3334 & 2794 \\
\hline $\mathrm{F}$ & Aspvreten, Sweden & $2567^{\mathrm{b}}$ & 2047 & 2386 & 2991 & 2591 \\
\hline G & Mace Head, Ireland & $1907^{\mathrm{a}}$ & 1015 & 1165 & 1488 & 1287 \\
\hline $\mathrm{H}$ & Melpitz, Germany & $4664^{\mathrm{c}}$ & 4135 & 5714 & 8335 & 6749 \\
\hline I & Sable Island, NS, Canada & $869^{\mathrm{d}}$ & 1141 & 1174 & 1253 & 1191 \\
\hline $\mathrm{J}$ & Thompson Farm, NH, USA & $7039^{\mathrm{e}}$ & 4299 & 4437 & 4749 & 4504 \\
\hline K & Trinidad Head, California, USA & $918^{\mathrm{a}}$ & 867 & 1129 & 1657 & 1367 \\
\hline $\mathrm{L}$ & Bondville, IL, USA & $5038^{a}$ & 3542 & 6440 & 11074 & 8220 \\
\hline M & Southern Great Plains, OK, USA & $5064^{\mathrm{a}}$ & 1688 & 2963 & 4936 & 3747 \\
\hline $\mathrm{N}$ & Mount Waliguan, China & $2030^{\mathrm{h}}$ & 915 & 1096 & 1385 & 1208 \\
\hline $\mathrm{O}$ & Mukteshwar, India & $2730^{\mathrm{i}}$ & 2421 & 3789 & 5564 & 4616 \\
\hline $\mathrm{P}$ & American Samoa, USA & $270^{\mathrm{a}}$ & 207 & 206 & 210 & 208 \\
\hline Q & Botsalano game reserve, S. Africa & $2340^{\mathrm{f}}$ & 1230 & 2334 & 4035 & 3099 \\
\hline $\mathrm{R}$ & Bago State forest, Australia & $1800^{\mathrm{g}}$ & 3509 & 4102 & 5740 & 4738 \\
\hline S & Cape Grim, Australia & $1203^{\mathrm{a}}$ & 558 & 618 & 769 & 677 \\
\hline $\mathrm{T}$ & Neumayer, Antarctica & $324^{\mathrm{a}}$ & 310 & 309 & 306 & 307 \\
\hline $\mathrm{U}$ & South Pole, Antarctica & $156^{\mathrm{a}}$ & 261 & 260 & 258 & 259 \\
\hline \multicolumn{7}{|c|}{ Statistic Coefficient } \\
\hline \multirow{3}{*}{\multicolumn{2}{|c|}{$\begin{array}{l}\text { Mean Absolute Error } \\
\text { Standard Deviation of Error } \\
\text { Coefficient of Determination }\end{array}$}} & 0 & 772.0 & 720.0 & 1285.9 & 925.9 \\
\hline & & 0 & 1070.7 & 1077.0 & 1856.9 & 1331.7 \\
\hline & & 1 & 0.697 & 0.692 & 0.595 & 0.644 \\
\hline
\end{tabular}

Sources of CN10 data: ${ }^{a}$ (World Data Centre for Aerosols, http://wdca.jrc.ec.europa.eu); ${ }^{b}$ Dal Maso et al. (2008); ${ }^{c}$ (CREATE Aerosol Database at NILU, http://tarantula.nilu.no/ projects/ccc/create/index.htm); ${ }^{\mathrm{d}}$ (NOAA ESRL/GMD Aerosol Database, http://www.cmdl.noaa.gov/aero); ${ }^{\mathrm{e}}$ Ziemba et al. (2006); ${ }^{\mathrm{f}}$ Laakso et al. (2008); ${ }^{\mathrm{g}}$ Suni et al. (2008); ${ }^{\mathrm{h}}$ Kivekäs et al. (2009); ${ }^{\mathrm{i}}$ Komppula et al. (2009).

diameter of $10 \mathrm{~nm}$ into the grid boxes, which is used to account for sub-grid scale nucleation, has a significant impact on the CN10 budget. As expected, the spatial patterns in the changes of CN10 associated with different primary sulfate emission assumptions are similar to that of CS (Fig. 1). Compared to the baseline case (FS2.5FN5), CN10 around the source regions decreases by $\sim 10-30 \%$ when the primary sulfate emission is excluded (i.e., case FS0) (Fig. 4b and f) and increases by $\sim 10-30 \%$ when $f_{\text {sulfate }}$ is increased from $2.5 \%$ to $5 \%$ (Fig. $4 \mathrm{~d}$ and $\mathrm{h}$ ). Again, the increase of $f_{\text {nucl }}$ value by a factor of 3 (from $5 \%$ to $15 \%$ ) has significant impact on CN10 near source regions (20-30\% change with peak value reaching $\sim 50 \%$ ). The exclusion of primary sulfate emission reduces the number concentration of primary emitted sulfate particles, increases the nucleation rate, and then increases the number concentration of freshly nucleated particles. These new particles grow to larger size and have significant contribution to the particle number concentration over clean re- mote regions. Near the anthropogenic sulfur source regions, the CN10 increased by nucleation is less than that of particles decreased by the exclusion of primary sulfate emission. As a result, CN10 is increased over remote regions and decreased over polluted regions when primary sulfate emission is excluded. The FS2.5FN15 and FS5FN5 simulations indicate that both increases of $f_{\text {sulfate }}$ and $f_{\text {nucl }}$ can significantly increase the $\mathrm{CN} 10$ over source regions.

To assess the importance of proper primary particle emission parameterizations, we compare the predicted CN10 values with those observed at a number of surface-based stations which have long term continuous measurements. Figure 5 shows the $\mathrm{CN} 10$ values observed at the 21 boundary layer sites listed in Table 2 and the corresponding simulated values for the FS0, FS2.5FN5, FS2.5FN15 and FS5FN5 cases. As expected, primary sulfate emissions have significant impact on the $\mathrm{CN} 10$ values at the polluted sites but have relatively small influence on $\mathrm{CN} 10$ at remote sites. The 

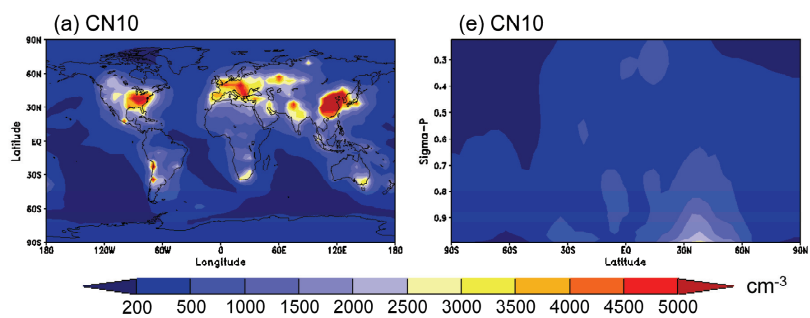

$200 \quad 500 \quad 10001500 \quad 2000 \quad 25003000 \quad 3500 \quad 40004500 \quad 5000$
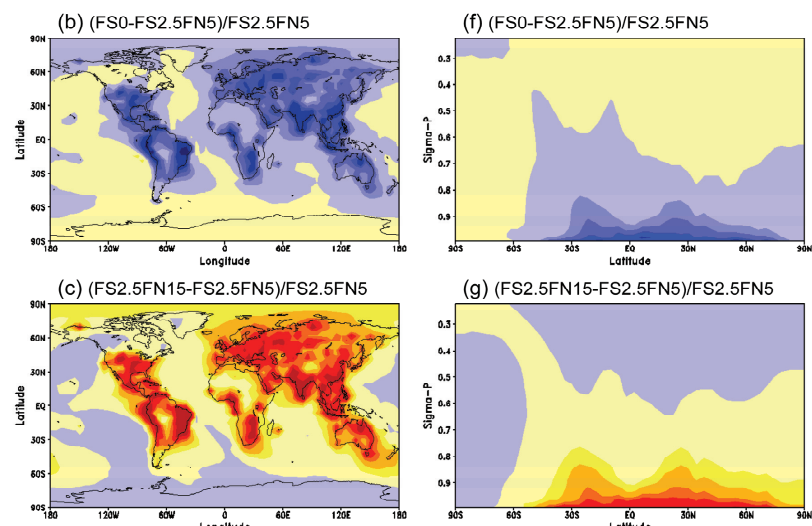

(g) (FS2.5FN15-FS2.5FN5)/FS2.5FN5
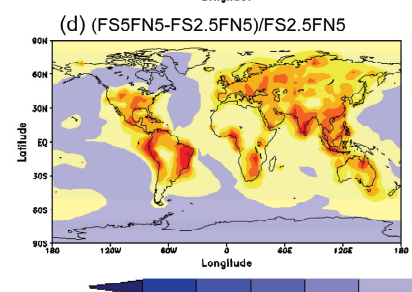

$\begin{array}{llllll}-50 & -30 & -20 & -10 & -5 & 0\end{array}$

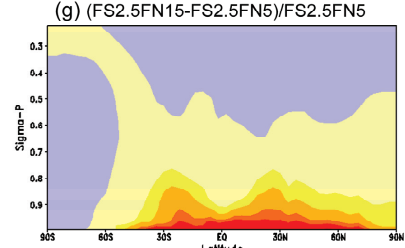

(h) (FS5FN5-FS2.5FN5)/FS2.5FN5

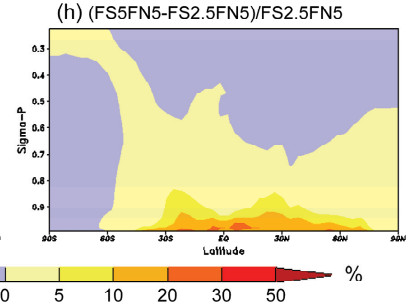

Fig. 4. Same as Fig. 1, except for the number concentration of condensation nuclei large than $10 \mathrm{~nm}(\mathrm{CN} 10)$.

statistic comparisons of the observations and the four sensitivity study cases at the 21 sites are also presented in Table 2. The FS2.5FN5 simulation is the baseline case. The coefficient of determination $\left(R^{2}\right)$ is simply the square of the sample correlation coefficient between the observations and their predicted values. The statistic comparisons indicate that the coefficient of determination is within 0.1 for all the four studied cases but the difference in the mean absolute error and standard deviation of error is much bigger. While the mean absolute error and standard deviation of error of the FS0 case are very close to the values of FS2.5FN5 case, those for the FS2.5FN15 and FS5FN5 simulations are much larger. For example, the mean absolute error and standard deviation of error of the FS2.5FN15 case are 1285.9 and 1856.9, respectively, which are about two times higher than those of the FS2.5FN5 case. As shown in Fig. 5b, the FS2.5FN15 and FS5FN5 cases over predict the CN10 at most polluted sites. The impacts of primary emission of sulfate on aerosol nucleation, particle number concentration and $\mathrm{CCN}$ number concentration mainly depend on the total number and surface area of primary sulfate emitted in nucleation model which is associated both with $f_{\text {sulfate }}$
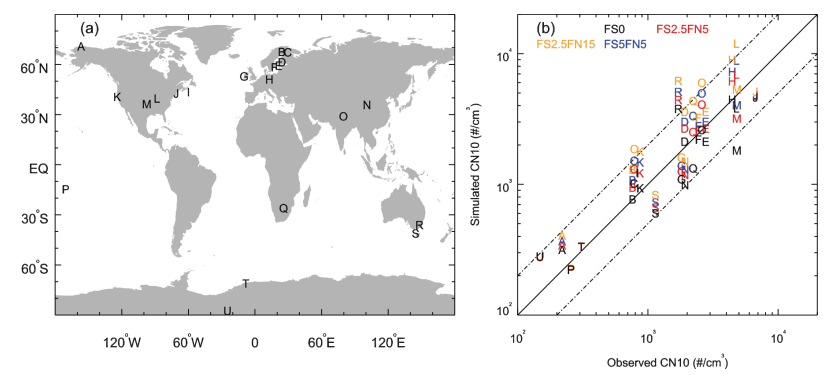

Fig. 5. (a) Locations of aerosol number concentration measurements used for simulation evaluation. Letters correspond to those listed in Table 2. (b) Comparison of observed and simulated annual mean number concentrations of $\mathrm{CN} 10$ at the 21 low boundary layer sites. The solid line shows a 1:1 ratio and the dashed lines show ratios of $1: 2$ and $2: 1$.

and $f_{\text {nucl }}$. The total number and surface area of primary sulfate emitted in nucleation model when $f_{\text {nucl }}$ is changed from $5 \%$ to $15 \%$ are a factor of $3 / 2=1.5$ lager than those when $f_{\text {sulfate }}$ is changed from $2.5 \%$ to $5 \%$. A comparison of (FS2.5FN15-FS2.5FN5)/FS2.5FN5 (Fig. 4c) with (FS5FN5FS2.5FN5)/FS2.5FN5 (Fig. 4d) shows that the changes of $\mathrm{CN} 10$ at emission source regions in the FS2.5FN15 case are generally more than 2-3 times larger than those in the FS5FN5 case. This extra enhancement (above the factor of 1.5) is caused by the nonlinear contributions associated with aerosol nucleation and other microphysical processes. Our simulations indicate that the increase of the $f_{\text {nucl }}$ from Whitby 78 value of $5 \%$ to widely used value of $15 \%$ has more distinct impact on $\mathrm{CN} 10$ than that of the increase of $f_{\text {sulfate }}$ from $2.5 \%$ to $5 \%$. It is clear from Table 2 that, statistically, the increase of $f_{\text {sulfate }}$ from $0 \%$ to $2.5 \%$ (with $f_{\text {nucl }}=5 \%$ ) does not improve the agreement of predicted CN10 at the 21 sites with those of observations but further increase of either $f_{\text {sulfate }}$ from $2.5 \%$ to $5 \%$ (with $f_{\text {nucl }}=5 \%$ ) or $f_{\text {nucl }}$ from $5 \%$ to $15 \%$ (with $f_{\text {sulfate }}=2.5 \%$ ) substantially deteriorates the agreement.

We would like to acknowledge that the present comparisons are subject to the uncertainties in the model (emission, chemistry, microphysics, transport, and scavenging), observations (counting efficiency for small particles, etc.), and spatial inhomogeneity (grid-box average versus value at a specific location). While we show that $0-2.5 \%$ primary sulfate mass emission with $5 \%$ to the nucleation mode is in better agreement with the $\mathrm{CN} 10$ values observed at the 21 surface-based stations, it should be noted that this result is derived based on various assumptions used in the present model and is subject to various uncertainties. For example, all the existing global studies (including the present study) assume that both $f_{\text {sulfate }}$ and $f_{\text {nucl }}$ have no diurnal, seasonal, and spatial variations. However, both $f_{\text {sulfate }}$ and $f_{\text {nucl }}$ in the real atmosphere depend on $\mathrm{OH}$ concentrations and other parameters which have significant diurnal, seasonal, and spatial 
variations (e.g., Wilson, 1981). To determine the dependence of $f_{\text {sulfate }}$ and $f_{\text {nucl }}$ on key parameters and to properly represent such a dependency in the models are needed to reduce the uncertainty in predicted global aerosol number concentrations associated with primary sulfate emission parameterizations.

\subsection{Impact of primary sulfate emissions on $\mathrm{CCN}$ number concentrations}

The horizontal and vertical spatial distributions of $\mathrm{CCN}$ number concentration at $0.2 \%$ supersaturation $(\mathrm{CCN} 0.2)$ and the changes of $\mathrm{CCN} 0.2$ associated with primary sulfate emissions are shown in Fig. 6. Our simulations show that CCN0.2 in the boundary layer decreases by $\sim 6-18 \%$ over Europe, South Asia and East Asia when primary sulfate emission is excluded (Fig. 6b), while the maximum decrease of the zonally-averaged CCN0.2 appears at $\sim 30^{\circ} \mathrm{N}$ in the boundary layer (Fig. 6f). It is interesting to note that the CCN0.2 over several small regions is increased by $\sim 0-3 \%$ with the exclusion of primary sulfate emission, in large contrast with other locations within the boundary layer. Our analysis indicates that this is a result of complex interactions or competitions among nucleation, growth, transport, and scavenging. To assess the impact of $f_{\text {nucl }}$, we compare the CCN0.2 simulated by the FS2.5FN15 simulation with that simulated by the FS2.5FN5 simulation. As shown in Fig. 6c, the increase of $f_{\text {nucl }}$ from $5 \%$ to $15 \%$ increases CCN0.2 by $\sim 6-$ $18 \%$ over source regions and $\sim 0-3 \%$ over remote regions. The FS5FN5 simulation shows that the increase of $f_{\text {sulfate }}$ from $2.5 \%$ to $5 \%$ generally increases CCN0.2 (up to $3-12 \%$ over source regions over Asia and Southern America). The impact of $f_{\text {sulfate }}$ increased from $2.5 \%$ to $5 \%$ on $\mathrm{CCN} 0.2$ (Fig. 6d, h) is much less than that of $f_{\text {nucl }}$ increased from $5 \%$ to $15 \%$ (Fig. 6c, g), especially over high latitude regions in the Northern Hemisphere.

Table 3 shows that the change of $f_{\text {sulfate }}$ from $2.5 \%$ to $5 \%$ has relatively small impact on the change of global CCN0.2 $(\sim 3 \%)$. Compared to the FS0 case, FS2.5FN5 and FS5FN5 simulations indicate only $8-11 \%$ increase of CCN0.2 in the boundary layer and 3-5\% increase in the whole troposphere. The changes of $f_{\text {nucl }}$ from $5 \%$ to $15 \%$ can double the increase in the changes of the global CCN0.2 both in the boundary layer and in the whole troposphere. The strongest impact of primary sulfate emissions on global CCN0.2 appears in the FS2.5FN15 case, with the mean change of global CCN0.2 as high as $16 \%$ in the boundary layer and $8 \%$ in the whole troposphere. It is clear that $f_{\text {nucl }}$ value presents more significant impact on global CCN0.2 than that of $f_{\text {sulfate, high- }}$ lighting the importance in reducing the uncertainty associated with $f_{\text {nucl }}$ in order to reduce the uncertainties in the predicted global CCN0.2 concentrations.

Compared to the results from Wang and Penner (2009) $\left(f_{\text {sulfate }}=2 \%\right.$ with $\left.f_{\text {nucl }}=15 \%\right)$, the change of the CCN0.2 in the boundary layer of our FS2.5FN15 simulation is a fac-
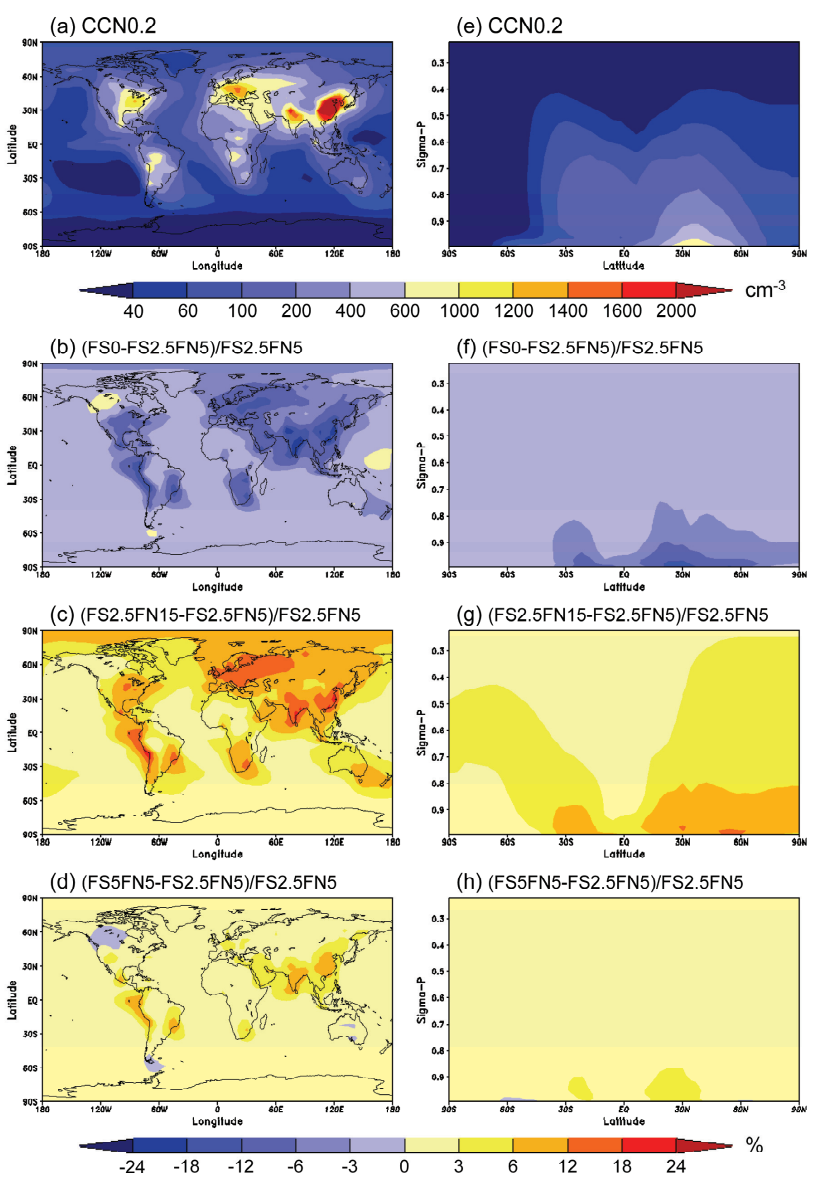

Fig. 6. Same as Fig. 1, except for the concentrations of cloud condensation nuclei at water supersaturation ratio of $0.2 \%$ (CCN0.2).

tor of 1.4 smaller than the BHN EMP case and a factor of 3.3 smaller than the BHN case. Because the two studies assumed the same value of $f_{\text {nucl }}$, the differences mainly arise from the different nucleation scheme employed, although other factors (such as parameterizations of other primary particles, particle growth and scavenging processes, etc.) could also contribute to the differences. When we use the Whitby 78 value of $f_{\text {nucl }}=5 \%$ instead of the widely used value of $f_{\text {nucl }}=15 \%$, the change of global CCN0.2 in boundary layer is decreased from $16 \%$ to $8 \%$. It is a factor of 2.9 smaller than the BHN EMP case and a factor of 6.6 smaller than the BHN case. The enhanced differences among these simulations are mainly due to the changed assumption of the fraction of primary sulfate mass in the nucleation mode.

\section{Summary and discussions}

The parameterization of sub-grid sulfur oxidation and sulfate particle formation in anthropogenic $\mathrm{SO}_{2}$ plumes, which has been named "primary sulfate" emissions in the literature, represents one of the major uncertainties in global cloud 
Table 3. A comparison of simulated impacts of different assumptions of primary sulfate emission on global annual mean CCN0.2. The percentage given in the table is the change relative to the case without any primary sulfate emission (i.e., FS $=0$ ).

\begin{tabular}{llrr}
\hline Cases & $\begin{array}{l}\text { Nucleation } \\
\text { theories }\end{array}$ & $\begin{array}{r}\text { Global } \\
\text { Boundary Layer }\end{array}$ & $\begin{array}{r}\text { Whole } \\
\text { Troposphere }\end{array}$ \\
\hline FS2.5FN5, this study & IMN & $8 \%$ & $3 \%$ \\
FS2.5FN15, this study & IMN & $16 \%$ & $8 \%$ \\
FS5FN5, this study & IMN & $11 \%$ & $5 \%$ \\
FS2FN15, Wang and Penner (2009) & BHN & $53 \%$ & \\
FS2FN15, Wang and Penner (2009) & BHN_EMP & $23 \%$ & \\
\hline
\end{tabular}

condensation nuclei $(\mathrm{CCN})$ predictions. Both the fraction of sulfur mass emitted as primary sulfate particles $\left(f_{\text {sulfate }}\right)$ and the fraction of primary sulfate mass distributed into the nucleation mode particles $\left(f_{\text {nucl }}\right)$ have large uncertainties. Here, we use a global size-resolved aerosol microphysics model to explore how the different parameterizations of primary sulfate particle emission affect nucleation, particle size distributions, and $\mathrm{CCN}$ number concentrations in the global troposphere. Different from previous studies, we use the ionmediated nucleation scheme to calculate new particle formation. In addition, the kinetic condensation of low-volatile SOG arising from oxidation aging on nucleated particles is considered. The effects of $f_{\text {nucl }}$ values on simulated CCN concentrations, which have not been investigated in previous studies, are investigated in the present study.

Our simulations clearly show a compensation effect of nucleation to primary sulfate emission. The inclusion of primary sulfate emission increases the surface area of preexisting particles, reduces $\left[\mathrm{H}_{2} \mathrm{SO}_{4}\right]$, and thus decreases nucleation rates near the source regions. When primary sulfate emission is reduced, the number concentrations of sulfate particles directly injected into the grid boxes decrease yet new particle formation rates near the source regions increase. This increase of nucleation rates compensates for some of the primary sulfate number emission reductions. However, enhanced nucleation cannot fully replace the role of sub-grid plume scale sulfur oxidant and nucleation processes, highlighting the necessity for proper parameterizations of these sub-grid processes in global aerosol models.

Our sensitivity studies indicate that the change of $f_{\text {nucl }}$ from the Whitby 78 value of $5 \%$ to the widely used value of $15 \%$ has a more significant impact on nucleation rates, particle size distributions, and $\mathrm{CCN}$ concentrations than that of $f_{\text {sulfate }}$ within the range of $2.5-5 \%$. The predicted annual mean $\mathrm{CN} 10$ values based on different primary particle emission parameterizations have been compared to those observed at 21 surface-based stations. Our statistical analysis shows that the increase of $f_{\text {sulfate }}$ from $0 \%$ to $2.5 \%$ (with $f_{\text {nucl }}=5 \%$ ) does not improve the agreement between predicted and observed $\mathrm{CN} 10$ at the 21 sites but further increase of either $f_{\text {sulfate }}$ from $2.5 \%$ to $5 \%$ (with $f_{\text {nucl }}=5 \%$ ) or $f_{\text {nucl }}$ from $5 \%$ to $15 \%$ (with $f_{\text {sulfate }}=2.5 \%$ ) substantially deteriorates the agreement.

When $f_{\text {sulfate }}=2.5 \%$ and $f_{\text {nucl }}=5-15 \%$ are assumed, our simulations indicate that the global CCN0.2 increases by $8-$ $16 \%$ in the boundary layer and $3-8 \%$ in the whole troposphere (compared to the case without primary sulfate emission, i.e., $f_{\text {sulfate }}=0$ ). Our predicted change of the CCN0.2 in the boundary layer for the FS2.5FN15 simulation is a factor of 1.4 and 3.3 smaller than that of the BHN EMP case and the BHN case in Wang and Penner (2009)'s study. These differences mainly arise from the different nucleation schemes employed. When we use $f_{\text {nucl }}=5 \%$ instead of $f_{\text {nucl }}=15 \%$, all the differences between our work and the work of Wang and Penner (2009) are doubled. The enhanced differences are mainly due to the changed assumption of the fraction of primary sulfate mass in the nucleation mode.

The impact of primary sulfate emissions on global CCN abundance derived in the present investigation, while much smaller than those from previous studies, is still significant especially in the boundary layer near source regions. Due to high sensitivity of aerosol indirect radiative forcing to $\mathrm{CCN}$ concentrations, it is necessary to further improve the representation of sulfur oxidation and sulfate particle formation in sub-grid scale $\mathrm{SO}_{2}$ plumes in regional and global models. All the existing global studies (including the present study) assume that both $f_{\text {sulfate }}$ and $f_{\text {nucl }}$ have no diurnal, seasonal, and spatial variations. However, both $f_{\text {sulfate }}$ and $f_{\text {nucl }}$ in the real atmosphere depend on $\mathrm{OH}$ concentrations and other parameters which have significant diurnal, seasonal, and spatial variations (e.g., Wilson, 1981). In order to reduce the uncertainties in the predicted global CCN concentrations and aerosol radiative forcing, further research (including observation) is needed to determine the dependence of $f_{\text {sulfate }}$ and $f_{\text {nucl }}$ on key parameters and properly represent such a dependency within climate models. It should be noted that the there may exist large uncertainty in the $f_{\text {nucl }}$ value derived by Whitby et al. (1978) because of instrument limitation. More measurements of particle size distributions and compositions in fresh power plant plumes using the modern instruments are needed to reduce the uncertainty in primary sulfate emission parameterizations. In addition to the primary sulfate 
emissions, many other processes (such as primary emissions of other species, particle nucleation and growth rates, particle scavenging rates, etc.) will also affect simulated global CCN concentrations and the uncertainties in these processes may affect the conclusion of this study. It is an ongoing task to improve the representation of these processes in global aerosol models.

Acknowledgements. This study is supported by NASA under grant NNX08AK48G and NSF under grant 0942106. The GEOS-Chem model is managed by the Atmospheric Chemistry Modeling Group at Harvard University with support from the NASA Atmospheric Chemistry Modeling and Analysis Program.

Edited by: N. Riemer

\section{References}

Adams, P. J. and Seinfeld, J. H.: Predicting global aerosol size distributions in general circulation models, J. Geophys. Res., 107(D19), 4370, doi:10.1029/2001JD001010, 2002.

Adams, P. J. and Seinfeld, J. H.: Disproportionate impact of particulate emissions on global cloud condensation nuclei concentrations, Geophys. Res. Lett., 30(5), 1239, doi:10.1029/2002GL016303, 2003.

Albrecht, B. A.: Aerosols, Cloud Microphysics, and Fractional Cloudiness, Science, 245(4923), 1227-1230, 1989.

Dal Maso, M., Hyvärinen, A., Komppula, M., Tunved, P., Kerminen, V., Lihavainen, H., Viisanen, Y., Hansson, H., and Kulmala, M.: Annual and interannual variation in boreal forest aerosol particle number and volume concentration and their connection to particle formation, Tellus, 60B, 495-508, 2008.

Evans, M. J. and Jacob, D. J.: Impact of new laboratory studies of $\mathrm{N}_{2} \mathrm{O}_{5}$ hydrolysis on global model budgets of tropospheric nitrogen oxides, ozone, and OH, Geophys. Res. Lett., 32, L09813, doi:10.1029/2005GL022469, 2005.

Fountoukis, C. and Nenes, A.: ISORROPIA II: a computationally efficient thermodynamic equilibrium model for $\mathrm{K}^{+} \mathrm{Ca}^{2+} \mathrm{Mg}^{2+} \mathrm{NH}_{4}^{+} \mathrm{Na}^{+} \mathrm{SO}_{4}^{2-} \mathrm{NO}_{3}^{-} \mathrm{Cl}^{-} \mathrm{H}_{2} \mathrm{O}$ aerosols, Atmos. Chem. Phys., 7, 4639-4659, doi:10.5194/acp-7-4639-2007, 2007.

Han, Q., Rossow, W. B., Chou, J., and Welch, R. M.: Global survey of the relationships of cloud albedo and liquid water path with droplet size using ISCCP, J. Climate, 11, 1516-1528, 1998.

Hartmann, D. L.: Radiative effects of clouds on Earth's climate, in: Aerosol-Cloud-Climate Interactions, edited by: Bobbs, P. V., Academic Press, 1993.

IPCC, Climate Change 2007: The Physical Scientific Basis, Rep., 996 pp., Cambridge Univ. Press, New York, USA, 2007.

Jimenez, J. L., Canagaratna, M. R., Donahue, N. M., Prevot, A. S. H., Zhang, Q., Kroll, J. H., DeCarlo, P. F., Allan, J. D., Coe, H., Ng, N. L., Aiken, A. C., Docherty, K. S., Ulbrich, I. M., Grieshop, A. P., Robinson, A. L., Duplissy, J., Smith, J. D., Wilson, K. R., Lanz, V. A., Hueglin, C., Sun, Y. L., Tian, J., Laaksonen, A., Raatikainen, T., Rautiainen, J., Vaattovaara, P., Ehn, M., Kulmala, M., Tomlinson, J. M., Collins, D. R., Cubison, M. J., Dunlea, E. J., Huffman, J. A., Onasch, T. B., Alfarra, M. R., Williams, P. I., Bower, K., Kondo, Y., Schneider, J., Drewnick,
F., Borrmann, S., Weimer, S., Demerjian, K., Salcedo, D., Cottrell, L., Griffin, R., Takami, A., Miyoshi, T., Hatakeyama, S., Shimono, A., Sun, J. Y., Zhang, Y. M., Dzepina, K., Kimmel, J. R., Sueper, D., Jayne, J. T., Herndon, S. C., Trimborn, A. M., Williams, L. R., Wood, E. C., Middlebrook, A. M., Kolb, C. E., Baltensperger, U., and Worsnop, D. R.: Evolution of Organic Aerosols in the Atmosphere, Science, 326, 1525-1529, 2009.

Kivekäs, N., Sun, J., Zhan, M., Kerminen, V.-M., Hyvärinen, A., Komppula, M., Viisanen, Y., Hong, N., Zhang, Y., Kulmala, M., Zhang, X.-C., Deli-Geer, and Lihavainen, H.: Long term particle size distribution measurements at Mount Waliguan, a highaltitude site in inland China, Atmos. Chem. Phys., 9, 5461-5474, doi:10.5194/acp-9-5461-2009, 2009.

Komppula, M., Lihavainen, H., Hyvärinen, A.-P., Kerminen, V.-M., Panwar, T. S., Sharma, V. P., and Viisanen, Y.: Physical properties of aerosol particles at a Himalayan background site in India, J. Geophys. Res., 114, D12202, doi:10.1029/2008JD011007, 2009.

Kuhns, H., Green, M., and Etyemezian, V.: Big Bend Regional Aerosol and Visibility Observational (BRAVO) Study Emissions InventoryRep., Desert Research Institute, Las Vegas, 2003.

Laakso, L., Laakso, H., Aalto, P. P., Keronen, P., Petäjä, T., Nieminen, T., Pohja, T., Siivola, E., Kulmala, M., Kgabi, N., Molefe, M., Mabaso, D., Phalatse, D., Pienaar, K., and Kerminen, V.-M.: Basic characteristics of atmospheric particles, trace gases and meteorology in a relatively clean Southern African Savannah environment, Atmos. Chem. Phys., 8, 4823-4839, doi:10.5194/acp-8-4823-2008, 2008.

Liao, H., Henze, D. K., Seinfeld, J. H., Wu, S., and Mickley, L. J.: Biogenic secondary organic aerosol over the United States: Comparison of climatological simulations with observations, J. Geophys. Res., 112, D06201, doi:10.1029/2006JD007813, 2007.

Luo, G., Yu, F., and Wang, Z.: Impact of aerosol on sea surface temperature over the subtropical Atlantic Ocean: A potential trigger factor of the NAO phase conversion? Geophys. Res. Lett., 36, L03708, doi:10.1029/2008g1036035, 2009.

Makkonen, R., Asmi, A., Korhonen, H., Kokkola, H., Järvenoja, S., Räisänen, P., Lehtinen, K. E. J., Laaksonen, A., Kerminen, V.M., Järvinen, H., Lohmann, U., Bennartz, R., Feichter, J., and Kulmala, M.: Sensitivity of aerosol concentrations and cloud properties to nucleation and secondary organic distribution in ECHAM5-HAM global circulation model, Atmos. Chem. Phys., 9, 1747-1766, doi:10.5194/acp-9-1747-2009, 2009.

Martin, R. V., Jacob, D. J., Yantosca, R. M., Chin, M., and Ginoux, P.: Global and regional decreases in tropospheric oxidants from photochemical effects of aerosols, J. Geophys. Res., 108(D3), 4097, doi:10.1029/2002JD002622, 2003.

Olivier, J. G. J., Berdowski, J. J. M., Peters, J. A. H. W., Bakker, J., Visschedijk A. J. H., and. Bloos, J.-P. J: Applications of EDGAR. Including a description of EDGAR 3.0: reference database with trend data for 1970-1995, Rep. RIVM report no. 773301 001/ NOP report no. 410200 051, 142 pp., RIVM, Bilthoven, 2001.

Park, R. J., Jacob, D. J., Field, B. D., Yantosca, R. M., and Chin, M.: Natural and transboundary pollution influences on sulfate-nitrate-ammonium aerosols in the United States: Implications for policy, J. Geophys. Res., 109, D15204, doi:10.1029/2003JD004473, 2004.

Pierce, J. R. and Adams, P. J.: Global evaluation of CCN formation by direct emission of sea salt and growth of ultrafine sea salt, J. 
Geophys. Res., 111, D06203, doi:10.1029/2005JD006186, 2006.

Pierce, J. R. and Adams, P. J.: Uncertainty in global CCN concentrations from uncertain aerosol nucleation and primary emission rates, Atmos. Chem. Phys., 9, 1339-1356, doi:10.5194/acp-91339-2009, 2009.

Platnick, S. and Twomey, S.: Determining the susceptibility of cloud albedo to changes in droplet concentration with the advanced very high resolution radiometer, J. Appl. Meteorol., 33, 334-347, 1994.

Spracklen, D. V., Pringle, K. J., Carslaw, K. S., Chipperfield, M. P., and Mann, G. W.: A global off-line model of sizeresolved aerosol microphysics: I. Model development and prediction of aerosol properties, Atmos. Chem. Phys., 5, 22272252, doi:10.5194/acp-5-2227-2005, 2005a.

Spracklen, D. V., Pringle, K. J., Carslaw, K. S., Chipperfield, M. P., and Mann, G. W.: A global off-line model of size-resolved aerosol microphysics: II. Identification of key uncertainties, Atmos. Chem. Phys., 5, 3233-3250, doi:10.5194/acp-5-3233-2005, 2005b.

Spracklen, D. V., Carslaw, K. S., Kulmala, M., Kerminen, V.-M., Sihto, S.-L., Riipinen, I., Merikanto, J., Mann, G. W., Chipperfield, P. M., Wiedensohler, A., Birmili, W., and Lihavainen, H.: Contribution of particle formation to global cloud condensation nuclei concentrations, Geophys. Res. Lett., 35, L06808, doi:10.1029/2007GL033038, 2008.

Streets, D. G., Bond, T. C., Carmichael, G. R., Fernandes, S. D., Fu, Q., He, D., Klimont, Z., Nelson, S. M., Tsai, N. Y., Wang, M. Q., Woo, J.-H., and Yarber, K. F.: An inventory of gaseous and primary aerosol emissions in Asia in the year 2000, J. Geophys. Res., 108(D21), 8809, doi:10.1029/2002JD003093, 2003.

Suni, T., Kulmala, M., Hirsikko, A., Bergman, T., Laakso, L., Aalto, P. P., Leuning, R., Cleugh, H., Zegelin, S., Hughes, D., van Gorsel, E., Kitchen, M., Vana, M., Hõrrak, U., Mirme, S., Mirme, A., Sevanto, S., Twining, J., and Tadros, C.: Formation and characteristics of ions and charged aerosol particles in a native Australian Eucalypt forest, Atmos. Chem. Phys., 8, 129-139, doi:10.5194/acp-8-129-2008, 2008.

Twomey, S.: The Influence of Pollution on the Shortwave Albedo of Clouds, J. Atmos. Sci., 34(7), 1149-1152, 1977.
Wang, M. and Penner, J. E.: Aerosol indirect forcing in a global model with particle nucleation, Atmos. Chem. Phys., 9, 239-260, doi:10.5194/acp-9-239-2009, 2009.

Whitby, K. T.: The physical characteristics of sulfur aerosols, Atmos. Environ., 12(1-3), 135-159, 1978.

Whitby, K. T., Cantrell, B. K., and Kittelson, D. B.: Nuclei formation rates in a coal-fired power plant plume, Atmos. Environ., 12(1-3), 313-321, 1978.

Wilson, W. E.: Sulfate formation in point source plumes: A review of recent studies, Atmos. Environ., 15, 2573-2581, 1981.

Yu, F.: Ion-mediated nucleation in the atmosphere: Key controlling parameters, implications, and look-up table, J. Geophy. Res., 115, D03206, doi:10.1029/2009JD012630, 2010.

Yu, F.: A secondary organic aerosol formation model considering successive oxidation aging and kinetic condensation of organic compounds: global scale implications, Atmos. Chem. Phys., 11, 1083-1099, doi:10.5194/acp-11-1083-2011, 2011.

Yu, F. and Luo, G.: Simulation of particle size distribution with a global aerosol model: contribution of nucleation to aerosol and CCN number concentrations, Atmos. Chem. Phys., 9, 76917710, doi:10.5194/acp-9-7691-2009, 2009.

Yu, F. and Turco, R.: Case studies of particle formation events observed in boreal forests: implications for nucleation mechanisms, Atmos. Chem. Phys., 8, 6085-6102, doi:10.5194/acp-86085-2008, 2008.

Yu, F., Wang, Z., Luo, G., and Turco, R.: Ion-mediated nucleation as an important global source of tropospheric aerosols, Atmos. Chem. Phys., 8, 2537-2554, doi:10.5194/acp-8-2537-2008, 2008.

Yu, F., Luo, G., Bates, T., Anderson, B., Clarke, A., Kapustin, V., Yantosca, R., Wang, Y., and Wu, S.: Spatial distributions of particle number concentrations in the global troposphere: Simulations, observations, and implications for nucleation mechanisms, J. Geophys. Res., 115, D17205, doi:10.1029/2009JD013473, 2010.

Ziemba, L. D., Griffin, R. J., and Talbot, R. W.: Observations of elevated particle number concentration events at a rural site in New England, J. Geophys. Res., 111, D23S34, doi:10.1029/2006JD007607, 2006. 